eCommons@AKU

June 2005

\title{
Prevalence of non-Helicobacter pylori duodenal ulcer in Karachi, Pakistan.
}

javed Yakoob

Aga Khan University, javed.yakoob@aku.edu

Wasim Jafri

Aga Khan University, wasim.jafri@aku.edu

nadim jafri

Aga Khan University

Muhammad Islam

Aga Khan University, muhammad.islam@aku.edu

Shahab Abid

Aga Khan University, shahab.abid@aku.edu

See next page for additional authors

Follow this and additional works at: http:/ /ecommons.aku.edu/

pakistan_fhs_mc_med_gastroenterol

Part of the Gastroenterology Commons

\section{Recommended Citation}

Yakoob, j., Jafri, W., jafri, n., Islam, M., Abid, S., Hamid, S., Shah, S., Shaikh, H. (2005). Prevalence of non-Helicobacter pylori duodenal ulcer in Karachi, Pakistan.. World journal of gastroenterology., 11(23), 3562-3565.

Available at: http://ecommons.aku.edu/pakistan_fhs_mc_med_gastroenterol/96 


\section{Authors}

javed Yakoob, Wasim Jafri, nadim jafri, Muhammad Islam, Shahab Abid, Saeed Hamid, Syed H Shah, and Hizbullah Shaikh 


\title{
Prevalence of non-Helicobacter pyloriduodenal ulcer in Karachi, Pakistan
}

\author{
Javed Yakoob, Wasim Jafri, Nadim Jafri, Muhammad Islam, Shahab Abid, Saeed Hamid, Hasnain AliShah, Hizbullah Shaikh
}

Javed Yakoob, Wasim Jafri, Nadim Jafri, Muhammad Islam, Shahab Abid, Saeed Hamid, Hasnain AliShah, Hizbullah Shaikh, Section of Gastroenterology, Department of Medicine and Pathology, Aga Khan University Hospital, Stadium Road, Karachi, Pakistan Correspondence to: Dr. Javed Yakoob, MBBS, Section of Gastroenterology, Department of Medicine, Aga Khan University Hospital, Stadium Road, Karachi, Pakistan. yakoobjaved@hotmail.com Telephone: +92-21-48594661 Fax: +92-21-4934294

Received: 2004-05-31 Accepted: 2004-07-10

\begin{abstract}
AIM: To determine the prevalence of non-Helicobacter pylori ( $H$ pylori)-related duodenal ulcer in patients with acid-peptic diseases.
\end{abstract}

METHODS: Medical records of patients who attended the Gastroenterology Department at Aga Khan University Hospital from 1999 to 2001 and had endoscopic diagnosis of duodenal ulcers were reviewed. Duodenal ulcer associated with $H$ pylori was diagnosed on the basis of endoscopy, rapid urease test and histopathology whereas histories of aspirin or other non-steroidal anti-inflammatory drugs (NSAIDs) related duodenal ulcers. Non- $H$ pylori, non-NSAID duodenal ulcers were those without $H$ pylori infection and history of NSAID intake. Co-morbid conditions associated were noted.

RESULTS: Of 2260 patients, 10\% (217/2 260) had duodenal ulcer. Duodenal ulcer related to $H$ pylori infection accounted for 53\% (116/217), NSAID-related 10\% (22/217), non- $H$ pylorinon-NSAID 29\% (62/217), and 8\% (17/217) had both $H$ pylori infection and histories of NSAID intake. Fifteen percent (18/116) patients had past histories of peptic ulcer disease in $H$ pylori infection, while $8 \%(5 / 62)$ in non- $H$ pylori non-NSAID ulcer. Co-morbid conditions in $H$ pylori infection were seen in 23\% (27/116) and 34\% $(21 / 62)$ in non- $H$ pylori non-NSAID ulcer.

CONCLUSION: Incidence of $H$ pylori infection related with duodenal ulcer is common. In the presence of co-morbids, non- $H$ pylori and non-NSAID duodenal ulcer is likely to be present.

(C) 2005 The WJG Press and Elsevier Inc. All rights reserved.

Key words: H pylori; Acid-peptic diseases

Yakoob J, Jafri W, Jafri N, Islam M, Abid S, Hamid S, AliShah $\mathrm{H}$, Shaikh $\mathrm{H}$. Prevalence of non-Helicobacter pylori duodenal ulcer in Karachi, Pakistan. World J Gastroenterol 2005; 11
(23): 3562-3565

http://www.wjgnet.com/1007-9327/11/3562.asp

\section{INTRODUCTION}

Peptic ulcer is a leading cause of morbidity and mortality. Helicobacter pylori (H pylori) infection and nonsteroidal anti-inflammatory drugs (NSAIDs) are recognized as the most important causes of peptic ulcer disease. H pylori infection is considered as a prerequisite for duodenal and gastric ulcers $^{[1,2]}$. The widespread use of NSAIDs has led to an increased incidence of ulcer complications. There has been an increase in admission for ulcer related complications among elderly people, which is attributed to the increased use of NSAIDs and low-dose aspirin ${ }^{[3]}$. An estimated 16500 patients with arthritis die from the gastrointestinal toxicity of NSAIDs every year ${ }^{[4]}$. The decline in prevalence of $H$ pylori infection in developed countries has changed the pattern of peptic ulcer diseases ${ }^{[5]}$. Studies from North America showed that $11-44 \%$ of peptic ulcers were not related to either of the two factors ${ }^{[6,7]}$. In a meta-analysis of duodenal ulcer trials in North America, $20 \%$ of patients had ulcer recurrence within 6 mo after the eradication of $H$ pylori $^{[8]}$. This is in contrast with studies from Asia where the prevalence of $H$ pylori infection is high and that of ulcers not related to $H$ pylori or NSAIDs is very low ${ }^{[9,10]}$. In Pakistan, $H$ pylori exposure rate increases with advancement of age and lowering of socioeconomic status ${ }^{[11]}$. In a study, the overall exposure rate to Hpylori in children was 33\% while in a group of adult dyspeptic patients undergoing upper gastrointestinal endoscopy, the prevalence of $H$ pylori infection investigated by histology and rapid urease test revealed that $H$ pylori was associated with $85 \%$ cases of duodenal ulcer ${ }^{[11,12]}$. The pattern of duodenal ulcer in Karachi, Pakistan, extending over 13 year from June 1976 to June 1989, demonstrated that duodenal ulcer occurred predominantly between the $3^{\text {rd }}$ and $5^{\text {th }}$ decade of life with a male-female ratio of $6: 1^{[13]}$. History of NSAID intake was present in only $5 \%$ of these cases ${ }^{[13]}$. The aim of this study was to determine the prevalence of non-H pylorirelated duodenal ulcer in our patients.

\section{MATERIALS AND METHODS}

This retrospective study was conducted at Aga Khan University Hospital, Karachi, Pakistan. It is a tertiary care center and used as a referral center for patients from all over the country. Medical records of patients who attended the endoscopy unit of Gastroenterology Department at Aga Khan University Hospital from 1999 to 2001 and ICD-9- 
CM coded as duodenal ulcers diagnosed by esophagogastroduodenoscopy (EGD) were reviewed. These patients included all referrals from both outpatient and hospital inpatient services. All the patients were included only once for analysis. Of these, 49\% (1 115/2 260) patients had chronic gastritis, $9 \%(198 / 2260)$ gastric ulcer, $32 \%(730 / 2260)$ duodenitis and $10 \%(217 / 2260)$ duodenal ulcer. H pylori infection was confirmed by rapid urease test and histopathology, which was later used as the gold standard for the diagnosis. Age, sex, co-morbid conditions, history of aspirin, NSAIDs, proton pump inhibitor (PPI), histamine-2 receptor blocker $\left(\mathrm{H}_{2}-\mathrm{RB}\right)$, antibiotics usage, etc., were noted. Co-morbid conditions included hypertension, ischemic heart disease, diabetes mellitus, dyslipidemia, arthritis, etc. NSAID/aspirin usage was defined as ingestion of at least one dose within 4 wk before endoscopy. The current treatment of duodenal ulcer and symptomatic relief that followed was noted. The treatment consisted of a PPI alone or in combination of clarithromycin and amoxicillin at a recommended dose for $1 \mathrm{wk}^{[14]}$. Complete relief was defined requiring no further medication while partial relief required maintenance treatment with a PPI or $\mathrm{H}_{2}-\mathrm{RB}$. The risk factors associated with peptic ulcer diseases such as smoking and alcoholism were also noted. The endoscopic lesions were defined as duodenal ulcer with a break of $\geqslant 5 \mathrm{~mm}$ in the mucosal surface with an apparent depth, duodenitis and signs of active bleeding such as oozing and visible blood vessels. Rapid urease test and histopathology results were also noted. Histopathology documented $H$ pylori infection in the presence of Gram negative curved bacilli on staining with hematoxylin-eosin (HE) in the presence of inflammation that was graded according to Sydney classification. In doubtful cases, Giemsa stain was used to stain the slides.

\section{Statistical analysis}

Results were expressed as mean \pm SD, with median range for al continuousvariables (age, dose, etc.) and number (percentage) for categorical data (gender, etc.). Univariate analysis was performed using Pearson's $\chi^{2}$ test, Fischer-exact test and the difference in mean was evaluated by independent sample $t$ test wherever appropriate. $P<0.05$ was considered statistically significant. Statistical interpretation of data was performed using the computerized software program SPSS version 10.0.

\section{RESULTS}

The number of EGDs performed for upper gastrointestinal symptoms over this period was 9000 . Of these, 2 260/9 000 had gastroduodenal diseases with $H$ pylori infection-related duodenal ulcer 53\% (116/217), NSAID related 10\% (22/217), non-H pylori non-NSAID 29\% (62/217), and both $H$ pylori and NSAID related $8 \%(17 / 217)$ (Table 1$)$. Those with NSAID-related duodenal ulcer had the highest mean age of $62 \pm 16.2$ years and lowest of $41 \pm 14.3$ years in $H$ pylori infection. In all groups there was a male dominance.

\section{Duodenal ulcer related to NSAID use and $H$ pylori infection}

Patients with NSAID-related duodenal ulcers had a higher male: female ratio of $4: 1$ with mean age of $62 \pm 16$ years (Table 1). Abdominal pain was common in $H$ pylori infection $54 \%$ (63/116) however, symptoms of abdominal pain, hematemesis and melena were relatively more in those with NSAID related duodenal ulcer covering 36\% (8/22) (Table 1). Endoscopic duodenitis and signs of active bleeding were seen in those with $H$ pylori infection-related and NSAID-related duodenal ulcers (Table 1). Patients with both $H$ pylori and NSAID-related duodenal ulcers had no

Table 1 Clinical detail of the patients with duodenal ulcer (mean $\pm S D$ )

\begin{tabular}{|c|c|c|c|c|}
\hline Variables & $\begin{array}{l}\text { H pylori } \\
\text { infection } \\
(n=116)\end{array}$ & $\begin{array}{l}\text { NSAIDs } \\
\text { related } \\
(n=22)\end{array}$ & $\begin{array}{c}\text { Non-H pylori } \\
\text { non-NSAIDs related } \\
(n=62)\end{array}$ & $\begin{array}{c}\text { H pylori and } \\
\text { NSAIDs related } \\
(n=17)\end{array}$ \\
\hline \multicolumn{5}{|l|}{ Gender } \\
\hline Male & 80 & 18 & 42 & 11 \\
\hline Female & 36 & 4 & 20 & 6 \\
\hline Mean age $\pm S D$ & $41 \pm 14.3$ & $62 \pm 16.2$ & $42 \pm 17$ & $53 \pm 13.6$ \\
\hline \multicolumn{5}{|l|}{ Symptoms } \\
\hline Abdominal pain & 63 & 6 & 30 & 8 \\
\hline Non-specific & 10 & 4 & 7 & 3 \\
\hline $\mathrm{AHM}$ & 10 & 8 & 12 & 6 \\
\hline Bloating & 33 & 4 & 13 & 3 \\
\hline \multicolumn{5}{|l|}{ Past history } \\
\hline Peptic ulcer & 18 & 4 & 5 & 1 \\
\hline Co-morbid & 27 & 13 & 21 & 11 \\
\hline \multicolumn{5}{|l|}{ Endoscopy } \\
\hline Duodenitis & 42 & 6 & 24 & 4 \\
\hline Active bleed & 8 & 4 & 4 & 2 \\
\hline \multicolumn{5}{|l|}{ Therapy } \\
\hline Triple therapy & 74 & 5 & 14 & 11 \\
\hline PPI & 37 & 14 & 43 & 6 \\
\hline $\mathrm{H}_{2}-\mathrm{RB}$ & 3 & 2 & 4 & - \\
\hline \multicolumn{5}{|l|}{ Symptom relief } \\
\hline Complete & 69 & $P=0.09$ & 47 & 12 \\
\hline Partial & 47 & 5 & 15 & 5 \\
\hline
\end{tabular}

$\mathrm{AHM}=$ abdominal pain with hematemesis and melena. 
Table 2 Co-morbid conditions associated with duodenal ulcer in different groups

\begin{tabular}{|c|c|c|c|c|}
\hline Co-morbid & $\begin{array}{l}\text { H pylori } \\
\text { infection } \\
(n=27)\end{array}$ & $\begin{array}{l}\text { NSAIDs } \\
\text { related } \\
(n=13)\end{array}$ & $\begin{array}{c}\text { Non-H pylori } \\
\text { non-NSAIDs related } \\
(n=21)\end{array}$ & $\begin{array}{c}\text { H pylori and } \\
\text { NSAIDs related } \\
\quad(n=11)\end{array}$ \\
\hline HTN & 12 & 3 & 9 & 1 \\
\hline DM & 5 & 1 & 3 & 2 \\
\hline IHD & 4 & 3 & 8 & 4 \\
\hline Arthritis & 6 & 6 & 1 & 4 \\
\hline
\end{tabular}

distinguishing features.

\section{H pylori and non-H pylori non-NSAID duodenal ulcer}

$H$ pylori and non-H pylori non-NSAID duodenal ulcer had a similar male:female ratio and mean age (Table 1). Co-morbid conditions were more common in non-H pylori non-NSAID, which were $34 \%(21 / 62)$ and $23 \%(27 / 116)$ in H pylori, respectively (Table 2 ). In the presence of co-morbid conditions, the likelihood of non- $H$ pylori non-NSAID duodenal ulcer was twice that of $H$ pylori infection odds ratio: 1.7; 95\%CI: (0.8-3.5). Symptoms, endoscopic duodenitis and signs of active bleeding were almost equally common in both groups (Table 1).

\section{Treatment of duodenal ulcer related to $H$ pylori infection, NSAIDs use and non-H pylori, non-NSAIDs}

Triple therapy was administered to 64\% (74/116) patients with $H$ pylori infection, while PPI was used in $69 \%(43 / 62)$ non- $H$ pylori non-NSAID ulcers and in $68 \%(15 / 22)$ NSAID-related ulcers (Table 1). These forms of treatment were associated with complete symptom relief of $H$ pylori infection in 59\% (69/116), NSAID-related ulcer in $77 \%$ $(17 / 22)$ and non- $H$ pylori non-NSAID ulcer in $76 \%(47 / 62)$, with partial relief in $41 \%(47 / 116), 23 \%(5 / 22)$ and $24 \%$ $(15 / 62)$, respectively $(P=0.09$, Table 1$)$.

\section{DISCUSSION}

It is known that not all ulcers are caused by $H$ pylori and that there is evidence that the proportion of non-H pylori ulcers is common. The present study demonstrated that $H$ pylori infection related duodenal ulcers accounted for 53\% and those associated with NSAIDs 10\% (Table 1). The NSAIDs used were conventional and not selective COX-2 inhibitors. The mean age and the male to female ratio of patients with NSAID-related duodenal ulcer were comparatively higher than those of other three groups (Table 1). We did not find any association between risk factors such as smoking and alcohol intake with duodenal ulcer in any group. Abdominal pain was frequent in all groups, the combination of abdominal pain, hematemesis and melena was prominently seen in association with non-H pylori nonNSAIDs. Past history of peptic ulcer diseases was present in Hpylori infection, none of these patients with past histories of peptic ulcer diseases was_found to be on maintenance PPI or $\mathrm{H}_{2}$-RB. In keeping with other studies, co-morbid conditions were commonly associated with non-H pylori nonNSAID-related duodenal ulcer ${ }^{[9,15]}$. As the sample size was small, it was not sufficient to compare these co-morbid conditions individually in each of the four groups. Endoscopic duodenitis and signs of active bleeding on endoscopy were not prominent in any particular group (Table 1). Duodenal ulcer related to $H$ pylori was treated with triple therapy but only $56 \%$ became completely symptom free (Table 1$)$. This might be attributed to yet undefined proportion of nonulcer dyspepsia patients with co-existent carriage of H pylori.

The implications of this study are that in this group of patients the incidence of $H$ pylori infection related duodenal ulcer compared with previous study by Kazi et a ${ }^{[12]}$, was low, this might be attributed to the eradication therapy of Hpylori infection, improvement of socio-economic and living conditions. Also, practice of indiscriminate use of antibiotics in our society might have contributed to this. Non-H pylori non-NSAID duodenal ulcers were also present in our population where there is a high incidence of $H$ pylori infection. Non-Hpylori non-NSAIDs-related duodenal ulcers were found_in 29\% (Table 1). However, a high incidence of non-H pylori non-NSAIDs duodenal ulcer on a retrospective study needs confirmation prospectively. Also, some cases of $H$ pylori infection might have been missed on both rapid urease test and histopathology. It is also known that in some of the critically ill patients with co-morbid conditions, stressrelated ulcers may occur. However, none of our patients was critically ill or from intensive care units. The mean age of our patients with $H$ pylori infection and non-H pylori nonNSAID duodenal ulcer was the same in contrast to studies in the West where non-H pylori non-NSAID duodenal ulcer patients were_of a higher age $\mathrm{e}^{[9]}$. This can be explained by $H$ pylori, host and environmental factors all having a role in peptic ulcer diseases. Etiological factors for the development of non-H pylori non-NSAID duodenal ulcer remain to be identified. In the presence of effective prophylactic agents, ulcer complications related to NSAIDs were high in our elderly patients.

In conclusion, H pylori infection-related duodenal ulcer is still common while NSAID-related duodenal ulcers occur in older age group. In the presence of co-morbid conditions, non-H pylori non-NSAID duodenal ulcers are likely to be present.

\section{REFERENCES}

1 NIH Consensus Conference. Helicobacter pylori in peptic ulcer disease. NIH Consensus Development Panel on Helicobacter pylori in Peptic Ulcer Disease. JAMA 1994; 272: 65-69

2 Current European concepts in the management of Helicobacter pylori infection. The Maastricht Consensus Report. European Helicobacter Pylori Study Group. Gut 1997; 41: 8-13

3 Higham J, Kang JY, Majeed A. Recent trends in admissions and mortality due to peptic ulcer in England: increasing frequency of haemorrhage among older subjects. Gut 2002; 50 460-464

4 Singh G, Triadafilopoulus G. Triadafilopoulos G. Epidemi- 
ology of NSAID induced gastrointestinal complications. J Rheumatol Suppl 1999; 56: 18-24

5 Jyotheeswaran S, Shah AN, Jin HO, Potter GD, Ona FV, Chey WY. Prevalence of Helicobacter pylori in peptic ulcer patients in greater Rochester, NY: is empirical triple therapy justified? Am J Gastroenterol 1998; 93: 574-578

6 Kurata JH, Nogawa AN. Meta-analysis of risk factors for peptic ulcer. Nonsteroidal antiinflammatory drugs, Helicobacter pylori, and smoking. J Clin Gastroenterol 1997; 24: $2-17$

7 Sprung DJ, Apter MN. What is the role of Helicobacter pylori in peptic ulcer and gastric cancer outside the big cities? J Clin Gastroenterol 1998; 26: 60-63

8 Laine L, Hopkins RJ, Girardi LS. Has the impact of Helicobacter pylori therapy on ulcer recurrence in the United States been overstated? A meta-analysis of rigorously designed trials. Am J Gastroenterol 1998; 93: 1409-1415

9 Chan HL, Wu JC, Chan FK, Choi CL, Ching JY, Lee YT, Leung WK, Lau JY, Chung SC, Sung JJ. Is non- Helicobacter pylori, non- NSAID peptic ulcer a common cause of upper GI bleeding? A prospective study of 977 patients. Gastrointest Endosc 2001; 53: 438-442

10 Nishikawa K, Sugiyama T, Kato M, Ishizuka J, Komatsu Y, Kagaya H, Katagiri M, Nishikawa S, Hokari K, Takeda $\mathrm{H}_{\text {, }}$ Asaka M. Non-Helicobacter pylori and non-NSAID peptic ulcer disease in the Japanese population. Eur J Gastroenterol Hepatol 2000; 12: 635-640

11 Qureshi H, Hafiz S, Medhi I. H pylori IgG antibodies in children. J Pak Med Assoc 1999; 49: 143-144

12 Kazi JI, Jafarey NA, Alam SM, Zuberi SJ, Kazi AM, Qureshi $\mathrm{H}$, Ahmed W. Association of Helicobacter pylori with acid peptic disease in Karachi. J Pak Med Assoc 1990; 40: 240-241

13 Ahmed W, Qureshi H, Alam SE, Zuberi SJ. Pattern of duodenal ulcer in Karachi. J Pak Med Assoc 1990; 40: 212-215

14 Wilde MI, McTavish D. Omeprazole. An update of its pharmacology and therapeutic use in acid-related disorders. Drugs 1994; 48: 91-132

15 Ciociola AA, McSorley DJ, Turner K, Sykes D, Palmer JB Helicobacter pylori infection rates in duodenal ulcer patients in the United States may be lower than previously estimated. Am J Gastroenterol 1999; 94: 1834-1840

Science Editor Ma JY and Wang XL, Guo SY Language Editor Elsevier HK 